\title{
Overcoming very late severe calcific stenosis due to two layers of under-expanded stents with intravascular lithotripsy treatment: a case report
}

\author{
Ata Doost ${ }^{1}$ and Richard Clugson ${ }^{1}$ \\ ${ }^{1}$ Fiona Stanley Hospital
}

May 8, 2021

\begin{abstract}
Under-expanded stents in calcific coronary stenoses are a common challenge for interventional cardiologists as we undertake more complex coronary interventions for older population cohorts. It results in short-term and long-term stent failure and adverse patient outcomes. These complex lesions can be treated after many years with intravascular lithotripsy (IVL-Shockwave).
\end{abstract}

\section{Hosted file}

IVL Manuscript 18012021.pdf available at https://authorea.com/users/412543/articles/521216overcoming-very-late-severe-calcific-stenosis-due-to-two-layers-of-under-expandedstents-with-intravascular-lithotripsy-treatment-a-case-report 

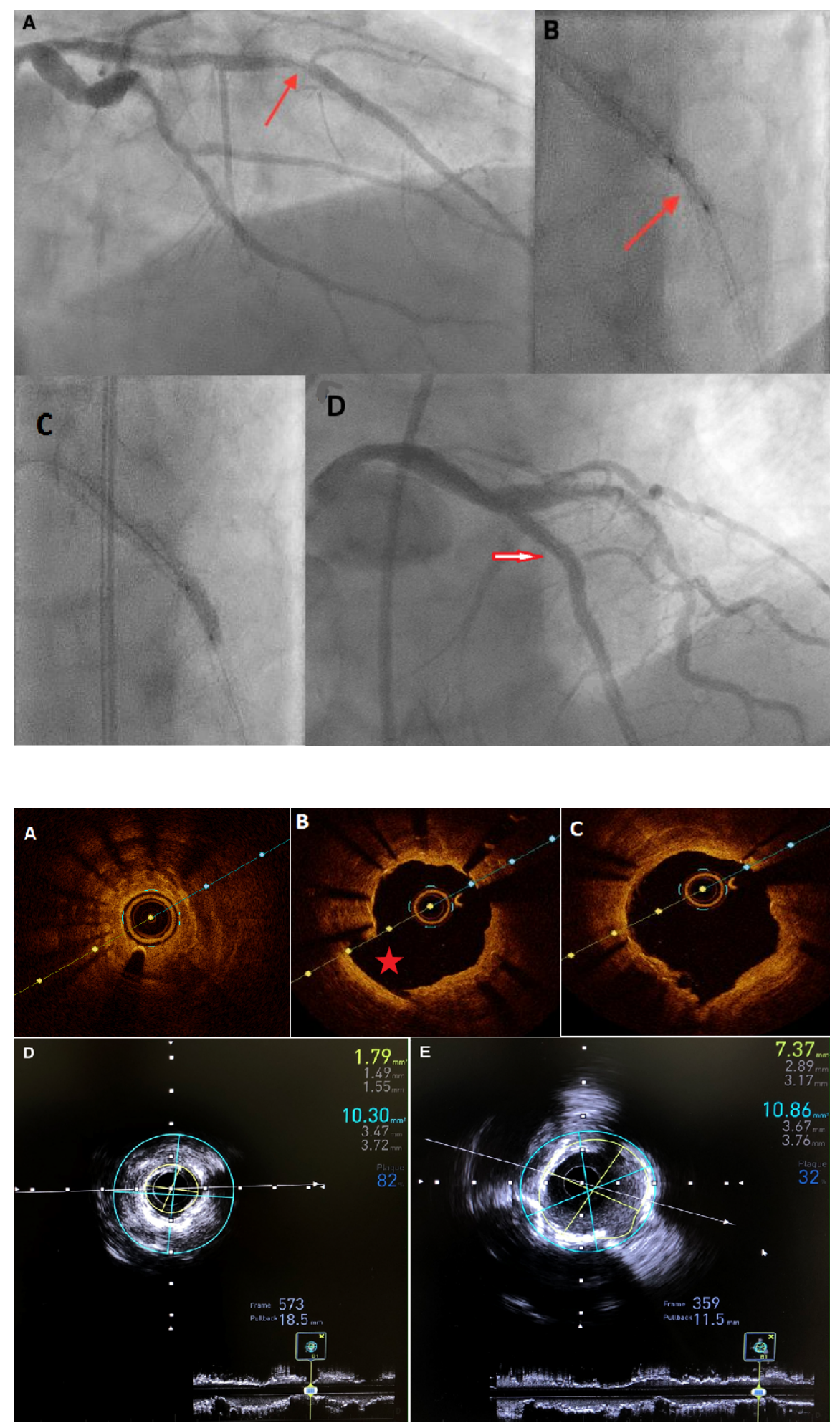